\title{
La revista Cormorán y su contribución al debate en torno a la cultura en la Unidad Popular*
}

\author{
The Cormorán Journal and its Contribution to the Debates about Culture in the \\ Unidad Popular
}

\author{
César Zamorano Díaz ${ }^{* *}$
}

\begin{abstract}
Resumen: El primer año de la Unidad Popular tuvo la intensidad acumulada por años de discusión y espera por legitimar una participación inclusiva en el diseño de la sociedad chilena. Ante ello, intelectuales, escritores y artistas quisieron contribuir a esta construcción de un nuevo Chile, no sin ello confrontar visiones y propuestas divergentes que promovieron interesantes debates, algunos más intensos que otros. La revista Cormorán (1969-70) constituye un instrumento capaz de dar cuenta de esta discusión, pues sirvió como dispositivo de intervención en los debates políticos y culturales de importantes figuras tanto nacionales como internacionales. Su propuesta, articulada por Enrique Lihn y Germán Marín, fue decisiva para proponer una nueva relación entre el arte y la política y confrontó al mismo tiempo algunas tendencias que pretendían instrumentalizar el arte desde propuestas ideológicas que para ellos no respondían a la naturaleza particular del proceso desarrollado durante la Unidad Popular.
\end{abstract}

Palabras clave: Unidad Popular, Revista Cormorán, Cultura, Política Cultural, Enrique Lihn.

\begin{abstract}
The first year of the Unidad Popular had the intensity accumulated through years of discussion and hopes in order to legitimize an inclusive participation in the design of Chilean society. In response, intellectuals, writers and artists wanted to contribute to the construction of a new Chile, not without it confront divergent views and proposals, promoted interesting debates, some more intense than others. Cormorán journal (1969-1970) is an essential instrument able to account for this discussion, since it served as a device intervention in political and cultural debates of important national and international leading figures. Its proposal, articulated by Enrique Lihn and Germán Marín were decisive in proposing a new relationship between art and politics and confronted, at the same time, some tendencies that expected to instrumentalize art from ideological proposals that they did not respond to the particular nature of the process developed during the Unidad Popular.
\end{abstract}

Keywords: Unidad Popular, Cormorán journal, Culture, Cultural Policy, Enrique Lihn

Recibido: 6 junio 2016

Aceptado: 23 agosto 2016

\footnotetext{
* Este trabajo forma parte del proyecto de investigación Postdoctoral Fondecyt-Conicyt de 2 años $\mathrm{N}^{\mathrm{o}}$ 3150496 "Revistas culturales en Chile (1970-1990) y la conformación de un campo cultural".

** Chileno. MA y PhD Hispanic Languages and Literatures, University of Pittsburgh. Editor y fundador revista Catedral Tomada. Miembro CEPIB (Centro de Estudios del Pensamiento Iberoamericano). Actualmente es investigador Postdoctoral Conicyt/Pontificia Universidad Católica de Chile.
} 
Los procesos políticos y sociales desarrollados durante la segunda mitad del siglo XX dieron como resultado el surgimiento de proyectos de izquierda más o menos hegemónicos en América Latina. En Chile, la llamada "vía chilena al socialismo" cautivó no sólo a las capas populares de la sociedad, sino a una amplia mayoría que vio en ella una real alternativa al capitalismo y a las condiciones de dependencia social y cultural en la que tanto Chile como latinoamérica han estado sumidas. Escritores e intelectuales no estuvieron ausentes en el debate en torno a contribuir en la construcción de este nuevo proyecto social. Podemos afirmar incluso que previamente a la Unidad Popular, en Chile se gestaba un rico y profundo diálogo en la esperada transformación social y la participación de cada uno de los agentes sociales. En este sentido, la literatura, el arte y la cultura en general fueron comprendidos como instancias decisivas en la construcción de una nueva sociedad y lugar privilegiado para recomponer una identidad nacional. De especial interés para comprender los debates y posiciones que se dieron cita durante aquella época son las revistas culturales, en las cuales se hicieron eco las efervescencias, conflictos y debates en torno a la función de la cultura y las artes en el proceso de socialización.

La tarea propuesta en este trabajo, se centra en comprender la relación del arte y cultura con la política durante uno de los periodos más intensos de la historia de Chile. La Unidad Popular, más allá de sus aciertos y sus errores, significó el intento de reconstruir las relaciones de poder y las definiciones sociales que diagraman las coordenadas sociales y sus producciones de subjetividades. La revista Cormorán, creada en 1969 y finalizada en 1970 constituye un instrumento de análisis que nos permitirá reconstruir los circuitos, relaciones y conflictos que permearon los primeros años de este periodo. Así, su análisis intentará articular la propuesta estético-política de la revista Cormorán y especialmente, desde la voz de su editor, el poeta Enrique Lihn, quien fue capaz de proponer estrategias tendientes a establecer lazos heterogéneos entre la academia y la sociedad, entre el arte y la política, entre el escritor y el pueblo. Planteamiento que para vislumbrarse en su contexto, requiere retomar ciertos elementos previos a la puesta en marcha del gobierno de Salvador Allende y al mismo tiempo, extenderse más allá de la vida de la revista. Sin embargo, y para efectos de no incurrir en generalidades, no será posible en este trabajo incluir a la totalidad de actores que hacen suyo estos debates. Me refiero específicamente a la revista La quinta rueda (1972-73) de la editorial estatal Quimantú y también la revista Cuadernos de la Realidad Nacional (1969-1973) del Centro de estudios de la Realidad Nacional (CEREN) de la Universidad Católica de Chile y dirigido por Jacques Chonchol, que articuló estos debates en torno a la cultura, con un fuerte acento en la cuestión de los medios de comunicación. ${ }^{1}$ Ante la imposibilidad de incorporar adecuadamente otras voces, nos limitaremos

\footnotetext{
${ }^{1}$ El trabajo comparativo entre las propuestas críticas del lugar de la cultura en el proceso de socialización están siendo desarrolladas en otro trabajo donde se ponen en diálogo el debate abordado en el presente artículo por Cormorán y continuado por el libro La cultura en la vía chilena al socialismo, junto a la discusión sobre esta materia que es desarrollada en el CEREN y La quinta rueda articulado principalmente, aunque no exclusivamente, por Carlos Maldonado y Armand Mattelart. Sobre este último, véase el libro que publicó junto a Mabel Piccini y Michéle Mattelart Los medios de comunicación de masas. La ideología de la prensa liberal en Chile publicado como número especial de Cuadernos de la Realidad Nacional en marzo de 1970 y un número importante de artículos aparecidos en La quinta rueda, donde podemos destacar el artículo "¿Dónde está la política cultural?" de Carlos Maldonado y Lucho Abarca.
} 
a la propuesta que es articulada desde la esfera universitaria ligada a una intelectualidad de izquierda heterogénea. ${ }^{2}$ De este modo, la revista Cormorán nos permitirá reconocer las discusiones y debates que se dieron cita en dos momentos: en el periodo inmediatamente previo al gobierno de la Unidad Popular, donde la reforma universitaria y el programa de gobierno de la candidatura de Salvador Allende modificaron el centro de gravedad de los debates; y la primera mitad del gobierno, donde comienzan a surgir las diferencias y propuestas disímiles en torno a la función de la cultura en la vía chilena al socialismo. Nuestra hipótesis es que Cormorán fue decisiva en contribuir al debate sobre el papel de la cultura en el proyecto de la Unidad Popular, desde una posición de izquierda no militante que defendió la autonomía relativa del arte con el fin de evitar concebir la práctica artística como suplemento representacional de una idealogía. Dicha propuesta, en diálogo y a ratos confrontación con otras intervenciones contribuyó en la formación de una poética de la Unidad Popular que reasignó un valor de la cultura y del arte en el conglomerado social y su relación siempre dinámica con la política.

\section{El proyecto de la Unidad Popular}

La discusión y proliferación en Chile de discursos tendientes a replantear el lugar de la cultura en los procesos revolucionarios, se remonta a los años sesenta. Lo que nos permite pensar que en este punto y en muchos otros, la Unidad Popular fue la culminación de un largo proceso de profundización y un compromiso colectivo con visiones de la izquierda. Dentro de los proyectos de revistas literaria/culturales de especial conotación se encuentra la revista Multitud (1939-1963), realizada por Pablo y Vinétt de Rokha que por más de 20 años logró un profundo diálogo entre el movimiento de trabajadores, principalmente del sector de la minería y la cultura y las letras. A principios de la década de los sesenta, hubo una abundante proliferación de revistas literarias, como soportes para la difusión de escritores jóvenes y la discusión en torno a la contingencia latinoamericana. Por ejemplo, la revista Árbol de letras (1967-1968) a cargo de Jorge Teillier y Antonio Avaria difundieron profusamente las obras e ideas de los escritores vinculados al boom en el marco de un apoyo incondicional a la revolución cubana. En sus once números, la revista contribuyó a crear las condiciones y abrir debates en torno al lugar de la cultura en los procesos revolucionarios que se estaban gestando en Latinoamérica y que continuarían fuertemente durante la UP. Hasta ese entonces, la reflexión de cómo pensar el lugar de la cultura en los procesos revolucionarios estuvo enfrentada a diagnosticar y proponer modelos sobre realidades, si no ajenas, al menos no enraizadas en la contingencia y condiciones particulares locales, con sus propios conflictos y fortalezas. En este sentido, durante la UP, los trabajadores de la cultura (como se solían llamar) comienzan a pensar y poner en práctica el ejercicio de su propia actividad. Esta vez, había que profundizar los lazos, intervenir las relaciones con otros modos y prácticas sociales.

\footnotetext{
${ }^{2}$ Para un análisis acerca de una confrontación entre una línea militante derivada principalmente del partido comunista y el grupo Cormorán, véase el excelente trabajo de Nadinne Canto Novoa "El lugar de la cultura en la vía chilena al socialismo. Notas sobre el proyecto estético de la Unidad Popular".
} 
La revista Cormorán nace en el contexto general de una serie de cambios y avances de las fuerzas de izquierda que dieron como resultado una nueva relación del arte y la cultura frente a los procesos políticos en desarrollo. En efecto, el arribo de la coalición de la Unidad Popular al gobierno en 1970 se puede comprender como un progresivo protagonismo de lo colectivo y a las capas populares como sujetos capaces de intervenir en la preparación de una sociedad democrática y pluralista. Se propone desde una radical oposición al control de una minoría privilegiada dueña de los recursos económicos y de las instituciones que conforman el estado. En líneas generales, el proyecto cultural de la UP se nutrió de un rechazo a la dependencia política y cultural de Chile, promoviendo la recuperación de una identidad nacional-popular. Las clases populares son percibidas como constituyentes de una posible identidad, y por tanto, el lugar que debía ser politizado por todos los medios, incluyendo la cultura. Lo popular se convirtió en la categoría medular de identidad colectiva, por lo que se hizo necesario recuperar sus manifestaciones artísticas y atender al mejoramiento de las condiciones de vida de una mayoría hasta entonces marginada y desligada del desarrollo social y cultural del país. Todo esto derivó persistentemente en una expansión de lo meramente nacional a un imaginario de mayor resonancia continental americana, como conjunto de pueblos bajo similares conflictos de colonialidad, explotación y marginalidad.

Este ambiente de efervescencia política de una creciente percepción de las fuerzas de base popular está definido en el Programa básico de gobierno de la Unidad Popular ${ }^{3}$ a través de la creación de comités populares con carácter electoral, capaces de ejercer una democracia directa que diera paso al "régimen político más democrático de la historia del país"(.p12) que modificaría el eje de poder controlado principalmente por el poder económico y las elites políticas.Apoyar al candidato de la Unidad Popular no significa, por tanto, solo votar por un hombre, sino también pronunciarse en favor del reemplazo urgente de la actual sociedad que se asienta en el dominio de los grandes capitalistas nacionales y extranjeros.(12)

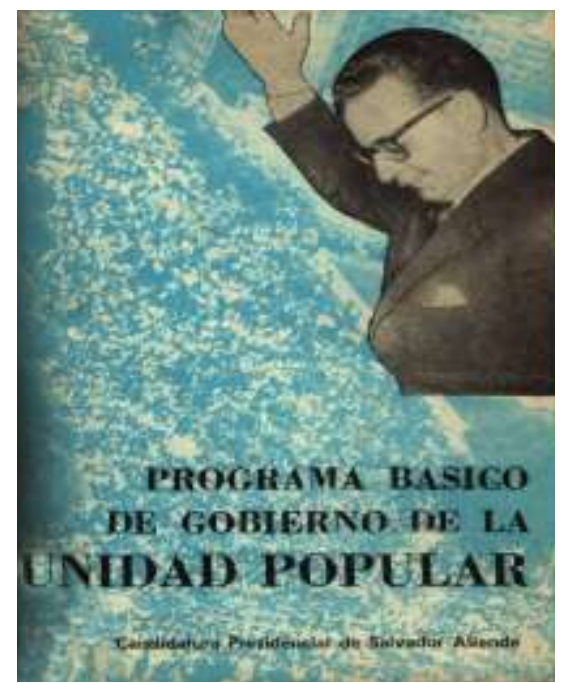

Imagen 1. Portada del Programa Básico de Gobierno de la Unidad Popular para la Candidatura de Salvador Allende en 1969.

\footnotetext{
${ }^{3}$ El programa fue aprobado por los partidos Comunista, Socialista, Radical y Social Demócrata, el Movimiento de Acción Popular Unitaria (MAPU) y la Acción Popular Independiente, el 17 de Diciembre de 1969 en Santiago de Chile.
} 
Esta apelación a lo popular se entiende en el contexto local y continental, como una crítica a toda una tradición que ha invisibilizado a una amplia mayoría de la población y ocultado sus avances reivindicativos crecientes y organizando sus fuerzas adecuadamente, lo que dio como resultado la llegada al control estatal de un gobierno que legitima como suya la fuerza popular. En contraposición, la historia de Chile, según consigna el historiador Gabriel Salazar, ha sido la historia del "patriciado", de las clases más acomodadas de la sociedad. Hasta 1948, solo la literatura hizo algún rescate de inspiración de las clases populares, al incorporar la figura de lo "criollo". Fue en esta fecha que el historiador J.C. Jobet denunciaba que la Historia ha sido hecha "en función de la oligarquía gobernante", descuidando el papel jugado por las capas populares. (Salazar 7) Luego de ello, las investigaciones en torno a las clases populares fueron definiéndose principalmente a partir de la explotación económica y represión de que eran objeto; desde los esfuerzos de las organizaciones proletarias para conquistar el poder y como expresión del "pueblo", representada por los partidos, sindicatos y sus militantes. Salazar reconoce en esta relación nacional-popular dos ideas que pueden ser pertinentes para entender el objetivo colectivo común que la Unidad Popular promovía como sentido. Por un lado, la nación como "proceso histórico pasado, concluido en el presente", sustentando en "un sentimiento común de mera identidad"; y el pueblo, sujeto social que atiende a un futuro, "con el potencial necesario para transformar específicamente las condiciones dadas, o herederas del pasado" (Salazar 13). Aquí lo nacional-popular no es definido por la historia de "la patria", la cual carece en sí misma de la fuerza movilizante de un conjunto social. Un elemento sustancial en la conformación colectiva es la memoria de un pasado (y la atención al presente como su resultado) entendido como conjunto de opresiones y la alienación que un grupo padece por otro grupo dominante, ya sea nacional (burguesía) o internacional (imperialismo norteamericano). Pero también, como segundo aspecto central, está la relación de solidaridad que se establece en las clases oprimidas, alegando la condición común de marginación y dominación por un lado y en un sentido positivo, que fue fuertemente potenciado durante la UP, como reacción liberadora capaz de provocar "la destrucción de los poderes alienantes por el pueblo mismo" (16) ${ }^{5}$

Desde este doble condición de lo popular surge un proyecto de política cultural definido en el programa básico de gobierno que presentó la candidatura de Salvador Allende. Promovida como medio de transformación social, la UP consignó a la cultura un rol determinante, definida por una democratización de sus prácticas, lo que suponía una transformación de su actividad:

La cultura nueva no se creará por decreto; ella surgirá de la lucha por la fraternidad contra el individualismo; por la valoración del trabajo contra su desprecio; por los valores nacionales contra la colonización cultural; por el acceso de las masas populares al arte, la literatura y los medios de comunicación contra su comercialización. (Corvalán et al. 28)

\footnotetext{
${ }^{4}$ Manuel Rojas y Nicomedes Guzmán son, a nuestro juicio, quienes con mayor acierto y decidido ímpetu hicieron del sujeto popular el protagonista de sus obras.

5 "La sociedad popular desalienada no es otra cosa que el pueblo ocupando su propio HOY, o sea toda la latitud y longitud de su solidaridad desalienante, no solo para negar a sus enemigos, sino, principalmente, para desarrollar su propia sociedad" (Salazar 17)
} 
Las expresiones artísticas, culturales y académicas se encaminaron hacia este proyecto desde varios frentes: por medio de una reforma universitaria que problematizó la institución universitaria como espacio de intervención política y social; una fuerte influencia de la teoría de la dependencia, promovida por la sociología; y una abundante producción musical de un neofolclore, más conocido como "Nueva Canción Chilena" con figuras como Víctor Jara, IntiIllimani, Patricio Manns, Violeta Parra, entre otros. La cultura y las artes producirían el desarrollo de una conciencia crítica frente a las condiciones de explotación existentes, con el fin de liberar al hombre de la ignorancia en la que había estado sometido y llevando al país hacia una independencia cultural como destino. Este proyecto de la izquierda chilena, que no difiere radicalmente de un programa general americanista en torno a la figura del Hombre Nuevo, para Martín Bowen Silva sería localmente, "un ambicioso programa inmunológico destinado a reforzar la cobertura crítica que mediaría entre los individuos o grupos sociales y los mensajes o representaciones sociales circulantes" (11). La cultura se proyecta como instancia de producción de una subjetividad colectiva que se perfila como instrumento de intervención crítica. Podemos dar muchos ejempos de partcipación activa de 1 acultura que hizo suye este proceso político. Entre ellos, hubo un amplio compromiso y desarrollo del cine local, que incluyó muchas producciones de carácter netamente político y otras más experimentales. Miguel Littín, director y cineasta chileno de importantes producciones, entre las que se destaca "El chacal de Nahueltoro" (1969) afirmaba:

Creo en el cine como un instrumento de liberación, no creo en la propaganda ni en el panfleto. Liberación, para mí, es rescatar valores, es buscar en las culturas populares, es intentar darle rostro y fisonomía a un pueblo. Un pueblo con cultura propia es un pueblo que existe, resiste y se libera. Intentemos hacer un cine nuevo, agresivo, concientizador. (8)

Esta afirmación de establecer un vínculo más estrecho entre el cine la transformación social también fue una postura colectiva que llevó a la publicación una declaración titulada $E l$ Manifiesto de los Cineastas de la Unidad Popular, donde proponían construir "una cultura auténticamente nacional, y por consiguiente, revolucionaria" afirmando decididamente que "el cine chileno, por imperativo histórico, deberá ser un arte revolucionario"(Mouesca 53)

En un plano de transformación académica, la reforma universitaria que comienza en 1967 y que se profundiza durante la UP intensificó las relaciones entre la sociedad y la universidad, rompiendo paulatinamente con una nefasta tradición que llevó a las instituciones universitarias a convertirse en centros de privilegios completamente desligados de la sociedad. La reforma universitaria en su constitución medular comprende un interés creciente por resolver una escindida relación entre saber y sociedad, cultura y política, en la articulación necesaria entre estas dos instancias que en una sociedad segregado como la chilena, carecían de un encuentro armonioso. Los acontecimientos antes señalados permitieron abordar la transformación social que se estaba decantando durante el gobierno de la Unidad Popular, como un progresivo protagonismo que escritores, artistas y organismos ligados a la difusión y producción cultural sintieron que debían tener y es debido a estas expectativas que la discusión en torno al papel de la cultura en este proceso propiciara mayores exigencias haciéndose cada vez más intensas. La marginalidad de nuestra intelectualidad, se vio desplazada por una esperanza colectiva, en la 
medida que se entendía, en diferentes niveles y modalidades, que era fundamental atender a la formación y construcción de imaginarios. Es precisamente por esto que la cultura adquirió relevancia, como aquella instancia capaz construir una identidad colectiva, pero al mismo tiempo se incrementó la discusión en torno a su estructura y definición de una cierta autonomía relativa del campo cultural y sus modos de distribución, selección y consumo. Cormorán dio cuenta de esa efervescencia, intentó intervenir en el debate público y convocar afirmativamente el legítimo derecho y necesidad de participación de la intelectualidad en este escenario. Muchas de las propuestas que posteriormente se intentaron aplicar como instancias de una "política cultural" en los años siguientes de la UP, fueron planteadas por los integrantes de Cormorán, y sus discusiones que permean sus páginas, pueden contener los presagios no solo de su posibilidad, sino también de sus conflictos, de una necesaria comprensión de lo que significa ser escritor y artista, y cual vendría a ser el valor que una nueva política debía asignarle en la construcción de una nueva sociedad.

\section{Cormorán}

La revista Cormorán, dirigida por Enrique Lihn como editor y Germán Marín como jefe de redacción, comenzó en agosto de 1969 y terminó en 1970, alcanzando a publicar solo ocho números. Creada al alero de la Editorial Universitaria, al igual que su antecesora la revista Árbol de Letras que dirigió Antonio Avaria, el poeta Jorge Teillier y el diagramador Nelson Leivay con el mismo nombre que la primera colección chilena de libros de bolsillo que lanzó la editorial durante los años sesentas ${ }^{6}$. En términos generales, la revista Cormorán dio una amplia cobertura al campo cultural nacional. En literatura estuvieron presentes Nicanor Parra, Gerardo de Pompier (alter ego de Enrique Lihn), Jorge Guzmán, Luis Oyarzún, Pedro Lastra, por nombrar algunos. Pero su interés no se redujo a la literatura nacional, también incluyó debates y entrevistas en torno a escritores latinoamericanos como Mario Benedetti, Miguel Ángel Asturias ${ }^{7}$, Manuel Puig, Severo Sarduy, por nombrar algunos ${ }^{8}$. Abarcó diversas expresiones artísticas como el teatro, las artes plásticas, el cine en cuyas páginas cada una de éstas constituyó una sección particular más o menos permanente, permitiendo observar un amplio espectro de la actividad cultural tanto local como internacional. La estructura de la revista, compuesta sagradamente por dieciseis páginas, tuvo un número importante de reseñas y someras referencias al panorama cultural en secciones que se llamaron "Papel picado" "La caravana inmóvil" y un conjunto de trabajos de mayor extensión y profundidad que comprendía ensayos, entrevistas, mesas redondas, fragmentos de obras, etc.

\footnotetext{
6 "El sello estaba dividido en secciones como la de 'Letras de América', que dirigía Pedro Lastra, y otras de economía, política y filosofía, en las que asesoraban distintos especialistas". (www.universitaria.cl/historia)

${ }^{7}$ La revista contó con varios corresponsales en el extranjero, que en cada número daban cuenta de las publicaciones y de escritores que estaban dando que hablar por diversas partes del globo. Entre los que podemos destacar estaba el corresponsal en París Jean Michel Fossey quién realiza una entrevista a Miguel Ángel Asturias .y a Severo Sarduy, entre otros.

${ }^{8}$ Véase la entrevista realizada por Marín y Lihn a Mario Benedetti(Marín and Lihn) y la notable entrevista que se realizaron mutuamente Juan Carlos Onetti y Carlos Martínez Moreno.
} 


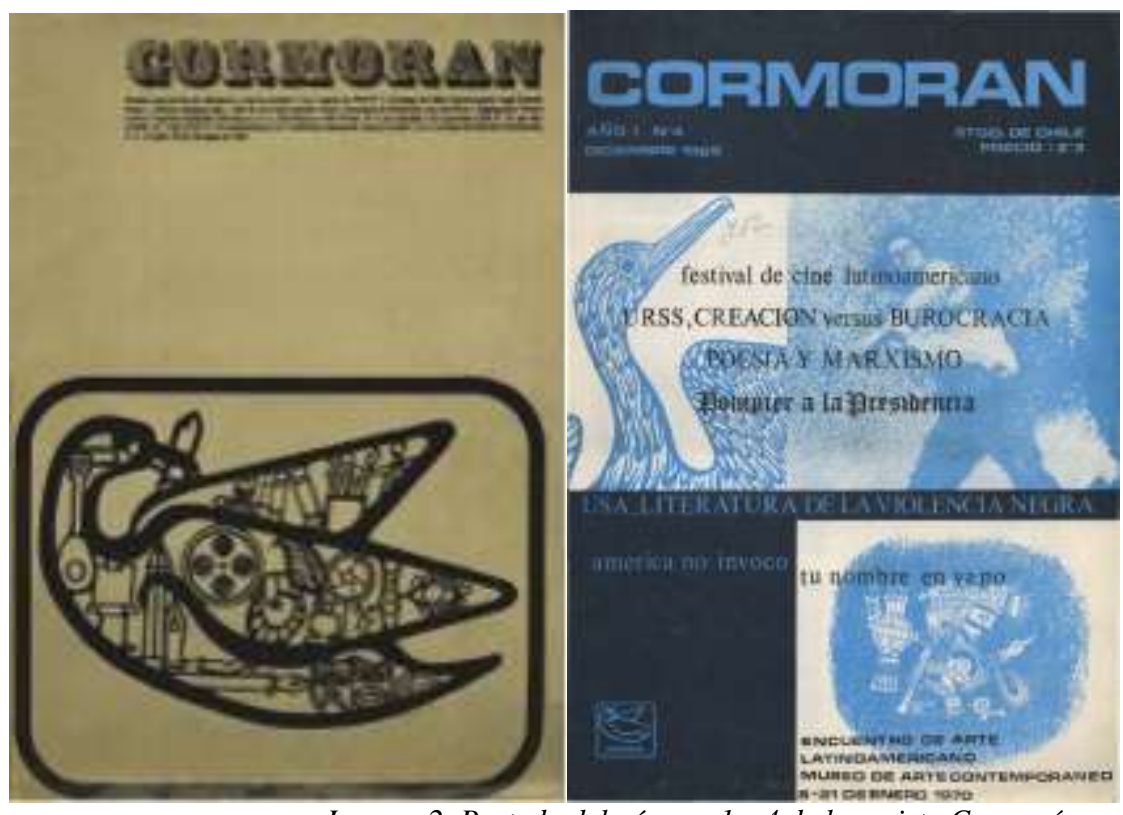

Esta diversidad de campos y propuestas artísticas respondía a un eje programático que ya en su primera editorial manifiesta. Se afirma allí que la revista se enmarca en "una visión global de la cultura en Chile, y de la necesaria apertura a la actualidad cultural extranjera" (Editorial). Esto constituyó un peculiaridad que difiere de las propuestas culturales de aquel entonces, sobre todo de aquellas que ligadas a la izquierda dieron cabida principalmente a la producción local y latinoamericana. Por el contrario, en Cormorán la literatura internacional no hispana también ocupó un lugar destacado, reseñando a connotados escritores de diversos lugares gracias a colaboradores que se encontraban fuera de Chile y que daban cuenta del estado de la literatura y el arte, principalmente de EEUU y Francia con Fernando Alegría y Jean Michel Fossey, respectivamente ${ }^{9}$. Pero sus inquietudes iban más allá de la mera divulgación, su interés fue más bien revitalizar "el examen crítico de nuestra situación cultural y de todo cuanto desde este ángulo pueda interesarnos verdaderamente" (Editorial). En este sentido, Cormorán fue un proyecto destinado no solo a difundir el arte y la cultura, sino también fue capaz de generar debates críticos en torno a las producciones artísticas nacionales e internacionales, intentar modificar los ejes programáticos imperantes y proponer alternativas capaces de intervenir desde el arte y la cultura el espacio de lo político. La revista sirvió de soporte para un conjunto de escritores y artistas involucrados activamente en el quehacer cultural efervescente de la época. En

\footnotetext{
${ }^{9}$ Podemos destacar el artículo dedicado a la reciente novela Soul on Ice del escritor y activista afroamericano norteamericano perteneciente al movimiento Black Panters Eldridge Cleaver cuyo tema central era la violencia racial durante aquella época. El artículo de Cristián Huneeus dedicado al novelista inglés William Golding a la obra de Scott Fitzgerald y un fragmento de su novela El último magnate. No podemos dejar de nombrar las entrevistas que realizó Fossey a Jean Genet y a Margarite Duras.
} 
este sentido, Cormorán fue determinante en visualizar, anteponerse a los procesos sociales y culturales que se estaban gestando apresuradamente.

La propuesta liderada por Enrique Lihn comprende un compromiso pero al mismo tiempo un intenso debate que se estaba gestando durante los años sesentas y que decante en el periodo de la Unidad Popular. En efecto, el proyecto revolucionario de Salvador Allende amplió un espectro incommensurable de posibilidades y tentativas conformadas por variadas interacciones y presupuestos teóricos y sociales. La efervescencia de la época, contribuyó a acrecentar los intentos que ya habían sido iniciados durante la reforma universitaria, de relación entre el arte y la sociedad, el conocimiento y el bien social al que este debe propender. Un buen ejemplo de esto y muy pertinente para nuestro análisis, es el cambio que sufre la revista de la Atenea, perteneciente a la Universidad de Concepción que, en función de la victoria de Salvador Allende y la promesa de la Unidad Popular decide cambiar su nombre por Nueva Atenea. Así, su número de julio-septiembre de 1970, dirigido por Enrique Lihn, en su editorial que, aunque carece de autoría, no cabe duda que al menos podemos darle crédito a su director se afirma que:

Después del 4 de septiembre, la política asumida por Nueva Atenea, no puede ser más clara, pero sí menos expectante en lo que se refiere a la especificidad de su tarea. Desde hoy, el quehacer teórico y creador del país puede incidir en una praxis revolucionaria que apunte, desde todos los niveles de la actividad social, a erradicar nuestro subdesarrollo. (s/a "Editorial")

La intervención que sufre una revista académica como Atenea supone no solo como presupuesto la Unidad Popular, sino mas bien es esta última que resulta de un largo proceso de transformación social y cultural que propone una intervención profunda de relaciones y formas de habitar y que, nuevamente Enrique Lihn aportaría en concordancia con esto, en proponer un lugar de la cultura en este reparto, modificando la propuesta editorial de esta revista que "alguna vez pudo sentirse demasiado a gusto en la atmósfera de un humanismo un poco idílico, atraída, ante todo, por las Letras", por un sentido más integrador de las artes y la cultura "que acogerá en sus páginas los medios de expresión que, en los últimos decenios, han llegado en nuestro país a un cierto grado de madurez; el teatro, el folklore, el cine y la televisión”.

Esta transformación y diversificación de la cultura fue objeto de discusión por gran parte del grupo que conformó Cormorán y que dado el contexto local y limitado, constituía gran parte de la escena cultural nacional. En este sentido, las revistas culturales en general durante esta época y especialmente Cormorán se puede entender, siguiendo la definición de Ángel Rama, como parte de lo que denomina "revistas programáticas" que "apuntan a una transformación del medio cultural en un plano elevado de eficiencia creadora, aportando no solo creaciones originales, sino además, algo mucho más importante: ideas sobre literatura, ideas sobre la sociedad y el medio" (30). En esta misma línea Fernanda Beigel propone la idea de "editorialismo programático" (108), como proyectos destinados no solo a difundir el arte y la cultura, sino principalmente a generar debates críticos en torno a las producciones culturales vigentes, modificar los ejes programáticos imperantes y la propuesta muchas veces interdisciplinaria de alternativas culturales que intervengan el espacio de lo político.

Precisamente en sus páginas circularon los más importantes sucesos o eventos culturales que sin duda, nos permiten comprender el ambiente propicio para su precisión y una reflexión 
profunda y compleja entre la política y la cultura. Muchos de los colaboradores de la revista participaron activamente en la organización y desarrollo del Encuentro de Escritores Latinoamericanos realizado en Santiago y Viña del Mar en 1969, donde se reunieron importantes escritores nacionales e internacionales como Ángel Rama, Mario Benedetti, Mario Vargas Llosa, Juan Rulfo, Juan Carlos Onetti, entre otros. Dicho encuentro, que fue tema central de la segunda entrega de la revista, manifiesta el estado vivo y al mismo tiempo tensionado de un periodo donde como afirma Claudia Gilman el escritor deviene intelectual, señalando la fuerte imbricación entre el escritor y el revolucionario durante los años sesentas y setentas. En este sentido, Gilman plantea cómo las revistas "corroboran hasta qué punto los sujetos políticos se constituyen en el plano discursivo: ellos fueron uno de los escenarios donde los escritores se ratificaron como intelectuales en la medida en que pusieron su palabra en la dimensión pública"(462).

Esta dimensión en que un discurso teórico intenta intervenir en el espacio público es el que me interesa definir, pues constituye una forma en que el narrador, el teórico, el especialista, adquiere visibilidad y se pone en la contingencia de la palabra común para hacerse oír. Cormorán estuvo atento a dicho encuentro y en su segunda editorial afirma en un tono característicamente polémico:

¿Qué puede esperarse de un Encuentro de Escritores, de los escritores mismos de la literatura?

Para un sector de la opinión que, sin embargo, no se ha marginado del campo literario, este es el desideratum de la esterilidad, una tierra baldía a la vez que el sitio donde campea la vanilocuencia, el vedettismo, la frivolidad y otras enfermedades.

En la medida en que "se ha gestado en Latinoamerica una literatura que alcanza hoy categoría de consideración universal" -como lo ha presumido la Declaración de los Escritores Latinoamericanos reunidos en Viña del Mar- aumenta entre ellos, sin excluir a algunos de los que gozan de esa consideración presunta, la desconfianza hacia su propio oficio. Vivimos, en este sentido, nuestra "edad de la sospecha", y es preciso separar en ella la paja del grano: su fundamento objetivo de los ingredientes. El odio a la literatura o el escepticismo más radical con respecto a ella, son fenómenos observables entre los escritores. Como contrapartida de los sentimientos negativos, la autocomplacencia y la vanidad, distorsionan también el significado del oficio literario, de donde una reunión como esta es una buena oportunidad para registrar las exageraciones en uno u otro sentido. (s/a "Editorial")

Al mismo tiempo, inmediatamente después de esta reunión, fue posible realizar un inédito encuentro en el congreso nacional el 19 de agosto de 1969 entre escritores y parlamentarios en torno a pensar la labor del escritor y el político en la sociedad que fue consignado en un documento titulado Encuentro Latinoamericano de escritores, publicado por la Cámara de Diputados, lo que demuestra el nivel de posicionamiento que los "trabajadores de la cultura" estaban adquiriendo durante este periodo. Podemos destacar que muchos de aquellos escritores y críticos también formaban parte del Taller de Escritores de la Universidad Católica, organizado por el mismo Lihn y Luis Domínguez en 1969. Cormorán difundió también el Segundo Festival de cine Latinoamericano y Segundo Encuentro Latinoamericano de Cineastas, realizado en Viña 
del Mar del 25 al 31 de octubre de 1969 organizado por el Departamento de Arte Cinematográfico de la Universidad de Chile. ${ }^{10}$

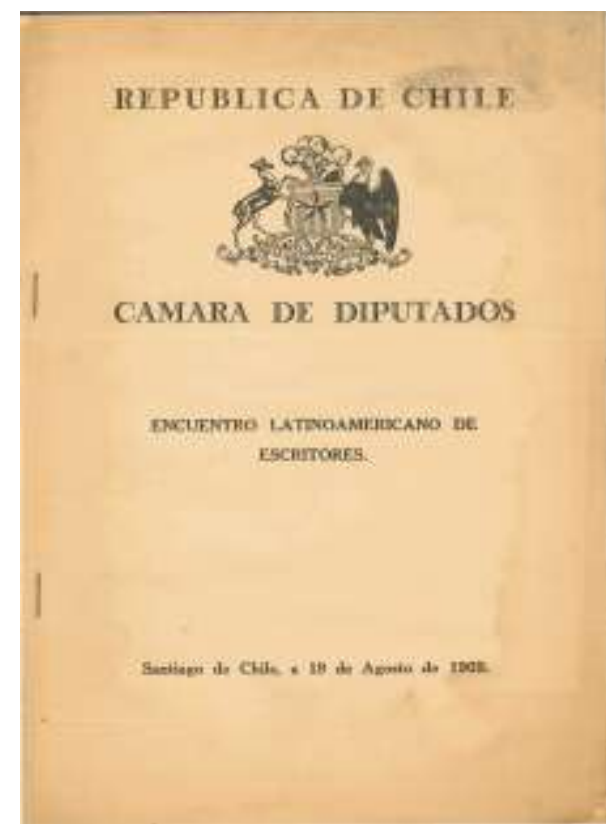

Imagen 3. Portada de documento titulado Diálogo con parlamentarios. El escritor y el legislador, emitido por la Cámara de Diputados en 1969.

\section{Cultura y sociedad: un debate}

Uno de los errores de pensar idealmente tendencias, procesos y proyectos, desligándolos de la conflictividad que los constituye, es que su desenmascaramiento resulta sencillo y el ideal puro y cristalino se desvanece ante las asimetrías y conflictos que se quieren ocultar. En este sentido, pese a orbitar en torno a los procesos de socialización y esperanzas de amplios sectores progresistas de la sociedad, diversas tendencias circularon con una premura irrepetible, dado el contexto sociopolítico que abrió grandes expectativas no solo en sectores marginados desde la Independencia, sino también en artistas, escritores e intelectuales que vieron en este proceso el momento decisivo para vincularse e influir decisivamente en la política y los procesos sociales en curso. Cormorán formó parte de toda esta gama de intervenciones y su aporte no estuvo exenta de polémicas e intensos debates. Germán Marín recuerda que la revista contó con el precario patrocinio de la Editorial Universitaria y el siempre escaso aporte económico de diversas entidades ${ }^{11}$, lo que la constituyó, desde su origen, como una revista "enclenque"

\footnotetext{
${ }^{10}$ Lihn y Marín realizaron entrevistas a tres exponentes del cine Latinoamericano que estuvieron presentes en el encuentro: los chilenos Miguel Littín, para hablar de su película El Chacal de Nahueltoro, Raúl Ruiz por Tres tristes tigres y al argentino Enrique Juárez, director de Ya es tiempo de violencia (1969)

${ }^{11}$ En otro lugar, el mismo Marín recuerda: "Si me atengo a la memoria, cabe señalar el de la Secretaría General de la Universidad de Chile, dirigida entonces por el joven economista Ricardo Lagos, quien preocupado de escucharnos con tranquilidad, nos invitó a su casa cierto sábado, en un departamento ubicado, si no me equivoco, en las Torres de Tajamar. Como se deduce, andábamos por la vida con el
} 
económicamente, en tanto "el auspiciador, la editorial Universitaria, esperaba la colaboración de sectores públicos, lo cual nunca ocurrió a cabalidad, acaso por la desconfianza que creábamos".(11) Su independencia de los bloques militantes partidistas, así como los modos de entender la cultura y las artes condicionaron una intensa, colaborativa, pero al mismo tiempo compleja relación con algunos de los modelos o prácticas que se estaban proponiendo. El mismo Marín se refiere a este lugar incómodo en el que la revista se situó:

Su consecución era improbable pues no ofrecía garantías a ningún partido político ni servía a nadie dado su perfil iconoclasta, situada entre los fuegos cruzados de una derecha enceguecida de odio que solo deseaba reventar el proceso y de una izquierda reduccionista cuyos agentes culturales, hoy algunos hijos pródigos del orden establecido, amparaban su oportunismo bajo una conducta sectaria. (11)

La revista Cormorán constituye una expresión manifiesta de intervenir en el desarrollo político de Chile contribuyendo a establecer ciertas bases de lo que será lo que podríamos llamar una política cultural de la Unidad Popular. Aunque tuvo una visión crítica como labor intrínseca de los intelectuales ante el devenir, siempre se mantuvo estrechamente ligada a los procesos sociales y sus páginas muestran un intento de hacer de la cultura un espacio privilegiado de las transformaciones sociales, reconociendo la particularidad del proceso chileno. En este sentido, su independencia partidaria no derivó en una desvinculación con el desarrollo político. Por el contrario, en todas sus editoriales define su participación en un debate al interior de una izquierda heterogénea que entiende el momento político y la función de la cultura desde diversas miradas. En su editorial del último número titulada "Nuevos días, nuevas metas" se señalan algunos lineamientos que la revista plantea en el nuevo escenario de una vía al socialismo inaugurada por el ascenso de la Unidad Popular:

En este sentido el proceso social que se iniciará a partir de las transformaciones estructurales programadas por el gobierno de la Unidad Popular, obliga a asumir las metas que una concepción diferente de la cultura deberá adoptar para colaborar en la tarea común de crear una sociedad nueva. Tal como ha sido señalado en cuanto que el trabajo humano será considerado como el más alto valor, la voluntad de afirmación e independencia nacional serán expresadas y una visión crítica de la realidad será a la vez conformada, se delinea una suerte de humanismo integral para quienes debemos ser partícipes como trabajadores de la cultura en este reto contra las estructuras obsoletas cuya trascendencia dependerá ahora del esfuerzo, lucidez y honestidad de cada uno de nosotros.

tarro duraznero a cuestas número a número de la revista, alternándonos con Enrique Lihn en dar la cara ante las pedidas que, a veces, terminaban en portazos, pues, como buenos caballeros chilenos, éramos pobres pero dignos. A través de esos esfuerzos se hicieron las siete u ocho entregas de "Cormorán" y del trabajo mismo de preparar sus páginas de creación, de reseñas, de crítica, puedo decir que constituyeron una fiesta del espíritu orquestada por el poeta Lihn y la ayuda impar de una musa de cabellos rubios". (http://www.universitaria.cl/historia) 
Esta revista indicó en su primer editorial (agosto/69) que sus páginas no estarían guiadas a registrar pasivamente el quehacer cultural sino a examinarlo desde una perspectiva crítica. Esta posición contiene en la hora actual una mayor responsabilidad por cuanto solidaria con las esperanzas que abrigan miles de asalariados chilenos, postergados hasta hoy por el sistema capitalista, no será neutral de modo alguno ante las contradicciones antagónicas que impidan a las masas incorporarse como consumidores y/o productores a la nueva cultura que deberá surgir del proceso de transformaciones que se inaugura.

Sin embargo, esta participación no fue tan armónica como se esperaba, incluso a ratos derivó en una clara confrontación con otras fuerzas que habitaron y se posicionaron de distintas maneras durante la Unidad Popular, que tenían visiones divergentes frente a algunos temas como si la cultura debía ser supeditada a las formas políticas partidarias, o qué se entiende por cultura nacional. También en consideraciones en torno a algunas distinciones del marxismo clásico acerca de la composición e identidad de lo popular como dimensión privilegiada, pasando por intentos de repetir procesos sociales de otras latitudes fueron objetos de discusión. La última cuestión resultó ser de vital importancia, debido a la fuerza que la revolución cubana tuvo en la intelectualidad latinoamericana respecto de valorar su desarrollo. Sin embargo, los escritores que participaron en Cormorán destacaron siempre el carácter democrático de la vía chilena al socialismo y esto significó estar siempre atentos a no replicar simplemente experiencias que en ese momento tenían cierto carácter hegemónico.

Para ejemplificar este debate, cabe destacar un documento publicado en su último número de 1970 llamado "Por la creación de una cultura popular y nacional", signado por un colectivo de escritores autodenominados Taller de Escritores de la Unidad Popular en la que firman 15 escritores $^{12}$. En este documento Cormorán asume una postura crítica pero cooperativa con la propuesta cultural que el programa de la Unidad Popular comprometió en su promesa de gobierno. Allí los firmantes plantean su compromiso con la izquierda y con la llamada "transición al socialismo" en la construcción de una política cultural coherente con ella, en donde la labor intelectual sería fundamental para el desarrollo de una conciencia crítica capaz de enfrentarse a las condiciones de explotación existentes, liberar al hombre de la ignorancia en la que ha estado sometido y llevar al país hacia una independencia cultural como destino. Una política cultural entonces proyectada como instancia de producción de una subjetividad colectiva.

\footnotetext{
${ }^{12}$ El documento fue firmado por los siguientes autores: Alfonso Calderón, Poli Délano, Luis Domínguez, Ariel Dorfmann, Jorge Edwards, Cristian Huneeus, Hernán Lavín Cerda, Enrique Lihn, Hernán Loyola, Germán Marín, Waldo Rojas, Antonio Skármeta, Federico Schopf y Hernán Valdés. Antecedente importante de este Taller que agrupa a la casi totalidad de los colaboradores de la revista Cormorán, es el Taller de Escritores de la Universidad Católica organizado por el mismo Lihn, Luis Domínguez en el año 1969. Véase el texto incompleto inédito "Un taller de poesía en 1972: Notas y reflexiones de una experiencia de trabajo" que presumiblemente fue escrito por Lihn en 1973.
} 


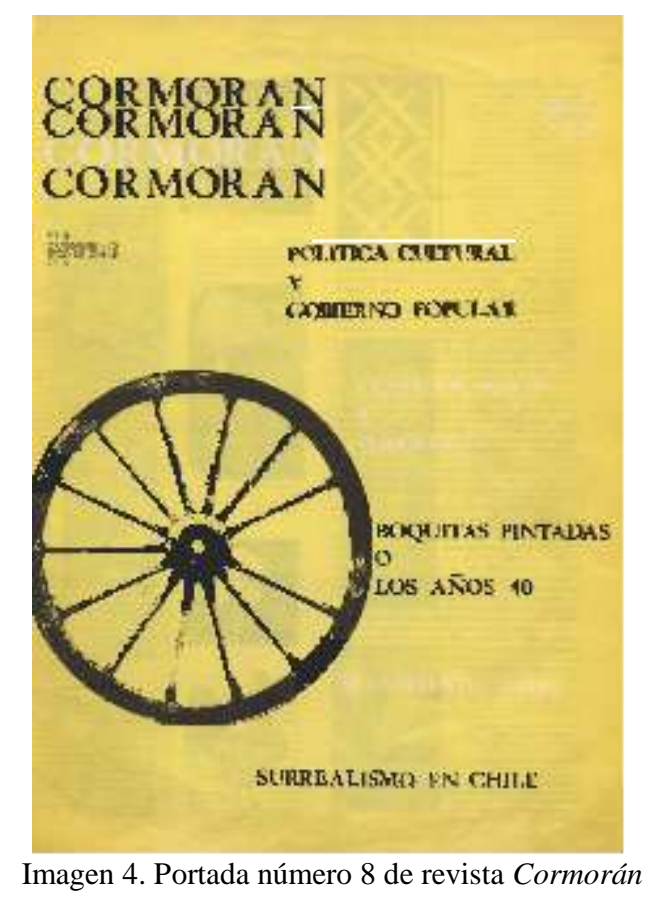

La cultura jugaría un papel fundamental en la toma de conciencia y de autoconciencia, que "solo será posible si la comunidad se redefine, busca expresarse y se da al esfuerzo constante de crear las imágenes de sí misma que la historia reclama" (7). Se señala que no es posible producir este cambio con solo incorporar a artistas e intelectuales en las estructuras de poder y desde allí expandir el saber a las masas populares. La cultura no sería una estructura previamente establecida, sino que debe construirse y diseñar modelos de comprensión de una identidad en desarrollo y para nada completa. Plantean lo que denominan "un proceso de culturalización de base nacional y popular" (7) que se opone a la mera divulgación de un gusto estético ya delimitado por las elites intelectuales. En orden a socializar la cultura, califica como un error de algunas propuestas de la función de las artes y la cultura en la vía chilena, pensar que bastaría simplemente "incorporar" a los artistas en el pueblo para su difusión o que solo sería necesario masificar la alta cultura. Según el texto firmado por el Taller de Escritores de la Unidad Popular, lo anterior entraña una actitud de estancamiento producto de un celo profesional tendiente a beneficiar a los artistas e intelectuales como gremio.

En cuanto a la actitud de nuestros intelectuales por integrarse en el nuevo proceso como profesionales de la cultura se hace necesario aquí, en primer término, la actitud paternalista, como la suposición de que habría una cultura lista para ser envasada, etiquetada y distribuida, y que solo faltaría ponerla al alcance de las masas (7)

También aparece en esta propuesta un intento por fijar las condiciones de profesionalización de los mismos que ya había sido objeto de en el encuentro de escritores 
latinoamericanos y desarrollado en diálogo con el parlamento en 1969. ${ }^{13}$ Dicha profesionalización no solo supone la idea gremial de mejorar las condiciones laborales de escritores y artistas, sino sobre todo concebir el lugar de los intelectuales en el marco social en tanto creador, difusor y organizador de una nueva cultura. Es decir, situar al intelectual como un facilitador y no fuente de una verdad establecida, que percibe su función social en actitud paternalista "inspirada en la noción general de que bastaría culturizar al desposeído, entendiéndolo como mero consumidor y no así como protagonista del proceso de culturalización iniciado en nuestros días"(7).

La propuesta parte de un diagnóstico de la sociedad embrutecida por el subdesarrollo y la dependencia, ambos rasgos inherentes de una historia que nos muestra la imposibilidad de construir una identidad propia, y desde donde la intelectualidad vendría a ser cómplice de este realidad en la medida en que ella es expresión de esta realidad, como colaboradora de las elites foráneas y dominantes, "entendiendo y utilizando la necesidad creadora del hombre en beneficio de su propio status" concluyendo drásticamente que "esta nuestra forma de alienación es simultáneamente nuestra única forma de expresión” (7). El documento clarifica a continuación cuales serían las características de su participación en la transformación social. El trabajador de la cultura cumpliría una función orientadora, que ha de ser una tarea constante, amplificada en varios ejes: como vanguardia del pensamiento, como crítica de un presente, que a su vez anticipe y proponga futuros, y como conciencia vigilante de los hitos y proyecciones que resulten como conclusiones. (7) Para ellos, la cultura es la que produce identidad y conforma los imaginarios

\footnotetext{
${ }^{13}$ En el llamado "encuentro latinoamericano de escritores" en la cámara de Diputados con los parlamentarios el 19 de agosto de 1969, donde participan diversos escritores tales como Humberto Díaz Casanueva, Ángel Rama, Mario Vargas Llosa, Germán Marín entre otros, así como editores y parlamentarios que intentaron a través de un diálogo inédito entre el arte y la política, definir elementos comunes a ambos campos de la experiencia humana. Se abre la sesión especial con la intervención de Héctor Valenzuela Valderrama, Presidente de la Cámara de Diputados:
}

Hemos estimado de gran importancia un encuentro entre parlamentarios y escritores en torno de un problema que nos atañe por igual: la función social del hombre. Se podría suponer que unos y otros desarrollan su actividad en campos cerrados y sin puntos de contacto; sin embargo, ambos modifican la realidad al configurarla en sus obras y ambos luchan por un intercambio viviente de las posibilidades humanas.(5)

Por otro lado y siguiendo esta misma línea, el diputado del partido radical Carlos Morales, piensa "que el escritor contemporáneo tiene la obligación de interpretar los anhelos del pueblo, los anhelos de las grandes mayorías nacionales, de los de abajo, de los que nada tienen" comprendiendo así al escritor como portavoz de una colectividad que "a través de sus obras, nosotros podemos recoger las inquietudes sociales que vive el mundo contemporáneo y traducir aquellas inquietudes [...]" (11). Sin embargo, las intervenciones no siempre tuvieron este tono conciliador y lleno de esperanzas. El escritor y legislador del Partido Comunista de Chile Volodia Teitelboim, se muestra escéptico frente a los frutos que este encuentro pueda generar "He aquí un momento, que yo califico de amor repentino, que, me temo, no va a fructificar en nada, o en casi nada[...] y de aquí a un año, el Parlamento chileno habrá probado si esta reunión tan hermosa, tan extraña, realmente, abrió un surco y produjo un fruto. (16) 
sociales que determinan la conciencia "Si ha de haber un ingreso al territorio de la libertad, el combate debe librarse donde estalla el conflicto" (7).

Los escritores agrupados en Cormorán apelaron a la destitución de la dependencia y los resabios totalitarios, pero fueron más allá del mero desmantelamiento de las instituciones y su carácter más visible y meramente represivo de sus prácticas. La cultura, en este sentido, constituiría un campo de lucha decisivo y en constante proceso de territorialización y desterritorialización, a través de los símbolos e imágenes que la componen. Lo que supone que solo la transformación de las instituciones económicas y sociopolíticas no bastaría para provocar modificaciones profundas:

La cultura se perfila como un instrumento de intervención crítica que permita una comprensión de nuestro ser que haga posible el proceso y que recoja sus experiencias. De otro modo, incluso el intento mismo de transformación de nuestras estructuras económicas resultará viciado. (7)

Es aquí donde se acrecienta una polémica que trasciende la vida de la revista. Sin ninguna mención que presumiera su término, Cormorán finaliza con esta octava entrega en diciembre de 1970. Un año más tarde, Enrique Lihn, Hernán Valdés, Cristian Huneeus, Carlos Ossa y Mauricio Wacquez publican La cultura en la vía chilena al socialismo. El trabajo publicado en este libro por Lihn llamado "Política y cultura en una etapa de transición al Socialismo" retoma las cuestiones mencionadas en la Declaración y con ello profundiza las diferencias con una izquierda más ortodoxa. Allí señala que fue precisamente esta última afirmación la que tuvo mayores repercusiones críticas pues produjo un fuerte rechazo en un sector de la izquierda derivada de una concepción economicista de la tesis de Marx en la cual afirma que "No es la conciencia de los hombres lo que determina su ser, sino por el contrario, su ser social es el que determina su conciencia"("Política y cultura" 26) Para el grupo Cormorán, el proceso de "transición al socialismo" necesita intervenir y comprender las formas de pensamiento, los mecanismos simbólicos que generan identidad en la sociedad chilena. Esto significa propiciar la autoconciencia como mecanismo para desprenderse de la dependencia y alienación social, de tal modo que los sujetos sean capaces de adquirir su propia determinación cultural y política. En este sentido, la apelación a la autoconciencia se enmarca al interior de una tradición marxista y los modelos socioculturales de la izquierda ampliamente desarrollados en Latinoamérica. Funcionó como crítica a la tradición liberal capitalista como causante del sistema de explotación y exclusión social, pero al mismo tiempo la conciencia de lo propio fue pensada como dispositivo de contención de una tendencia a pensar el proceso revolucionario chileno desde los derroteros de otras realidades originadas en contextos diferentes, fundamentalmente en Cuba y la Unión Soviética. Es así como Lihn distingue la revolución rusa que dada su particular situación, derivó en una dictadura del proletariado, de un "camino de Chile para Chile, de apertura revolucionaria y que, en conformidad al modelo adoptado en la práctica con el pluralismo ideológico, tendría que desembocar en una democracia socialista" (16) Para Lihn, la particularidad de la Unidad Popular sería la inclusión de una pluralidad inclusiva, que acoja no solo a las fuerzas políticas militantes, sino también aquellos que se situaban al margen de las consideraciones partidarias. 
Se trata, sin duda, de ampliar la base de apoyo social de la UP, rechazando la tendencia simplificadora con respecto a los antagonismos de clases; en el entendido de que el enfrentamiento de las mismas no tendría por qué ocurrir en Chile protagonizado, únicamente, por dos grandes bloques: la burguesía y el proletariado.

Si los modelos culturales habían sido definidos y reproducidos insistentemente con el fin de controlar y manipular a las masas aturdidas, sería necesaria una transformación mucho más profunda que la mera desarticulación de sus instituciones. La marginación de la potencia transformadora que puedan tener sectores no necesariamente identificables como proletarios, excluiría previamente un importante registro político y cultural de larga data en Chile. Tal como afirma Lihn, el propósito de esta declaración sería atender al problema político que la UP debe resolver, esto es, "el de ampliar su base de operaciones". (25) Así, desde un punto de vista de la inclusión de la cultura y el arte, el intelectual pequeño burgués sería capaz de contribuir al proyecto de la UP y no ser simplemente sustituido por "intelectuales orgánicos, obreros y campesinos" donde las capas populares se encuentran pauperizadas por las condiciones de marginalidad y los altos índices de analfabetización lo que bajo este escenario requeriría años de trabajo sostenido con el fin de crear masas populares conscientes y preparadas. Escritores y artistas, sus obras y subjetividades pueden participar junto con la cultura popular en un trabajo sostenido en un proceso de transición al socialismo que sea capaz de intervenir el cuerpo social adormilado.

Si atendemos a la transformación social como eje de la propuesta que la Unidad Popular planteaba, Lihn insiste que al no asumir la importancia fundamental de la cultura y las artes como elementos que con mayor eficacia estimulan una filiación con algunos imaginarios simbólicos que identifican a una sociedad como propios y al mismo tiempo entabla sus diferencias, quedará desarmado para continuar siendo apropiado por las capas más poderosas de la sociedad. Confrontación de un arte y la cultura entendido como expresiones que articulan deseos y perspectivas de mundo, expresión efectiva de una subjetividad en tanto relación con otro, que puede hacerse eco de una pulsión comunitaria, plural con unos medios culturales tradicionales que, ajenos a esta transformación y práctica colectiva, continuarán ejerciendo su derecho de ciudadanía y permeando las posibilidades de modificar las estructuras de pensamiento. Una cultura en diálogo con una política destinada a propiciar una nueva forma de compartir, que Nancy plantea como:

"Político" querría decir una comunidad que se ordena a la inoperancia de su comunicación, o destinada a dicha inoperancia: una comunidad que hace conscientemente la experiencia de su reparto. Alcanzar tal significación de lo "político" no depende, o en todo caso no llanamente, de lo que se llama una "voluntad política". Aquello implica estar ya involucrado en la comunidad, vale decir hacer, del modo que sea, la experiencia de la comunidad en cuanto comunicación: aquello implica escribir. No hay que dejar de escribir, dejar de exponerse el trazado singular de nuestro estar-en-común. (74)

Lo relevante de la intervención del grupo liderado por Enrique Lihn es precisamente la posibilidad de reconocer nuevas formas de subjetividades disidentes que en la escena cultural puedan ser potencialmente articuladoras de una resistencia a una pulsión totalitaria y reductiva de 
la imagen unívoca de un nuevo sujeto capaz de participar de una transformación radical de la sociedad y que se esparciría rápidamente en algunos proyectos revolucionarios en la forma de un reduccionismo proletario. En este sentido, sus planteamientos contienen los reflejos de un pensamiento comunitario y heterodoxo que ne conjunto con otras voces conformarían una suerte de Poética de la Unidad Popular.

\section{Pulsión comunitaria: hacia una Poética de la Unidad Popular}

Como pudimos notar, lejos de limar las asperezas provocadas por la declaración aparecida en Cormorán un año antes, el trabajo de Lihn aparecido en el libro de 1971 profundiza las diferencias frente a un economicismo e importación de modelos socialistas foráneos, abogando al carácter peculiar de su puesta en escena y que el propio presidente Allende legitima como vía chilena al socialismo. Para César Albornóz, este conflicto contiene una diferencia esencial entre visiones acerca de la cultura y su relación con la política. Se pregunta:

¿Había una contradicción entre cultura popular y libertad creativa? Sí, desde el punto de vista que manifestaciones ligadas a la cultura tradicional, o "alta cultura", y otras de origen extranjero, particularmente estadounidense como era el caso del rock, por muchos no se consideraban dignas del nuevo proceso, y tampoco se valoraban como expresión real. Por lo mismo, la capacidad para sintetizarlas en un todo común, nuevo y transgresor, pero igualmente comprometido y revolucionario, fue esporádica y marginal. (Albornóz 164)

Aquí cabe señalar algunos reparos. $\mathrm{Si}$ bien es cierto que, dado el proceso de transformación radical que se estaba viviendo en Chile, las discusiones respecto de la función de cada campo específico de la experiencia humana fue cuestionada, reconvertida y también en algunas ocasiones adquirió rasgos de confrontación. Sin embargo, también es efectivo que, incluso previamente a la puesta en marcha de la UP, la participación activa de artistas y escritores en los cambios sociales tuvo mayor visibilidad y, por tanto, sus dificultades y sus divergencias fueron notoriamente más sensibles ante la posibilidad de participación en el diseño e implementación de una nueva sociedad. El amplio y diverso repertorio de expresiones artísticas y la efervescencia cultural que se gestó antes y durante los tres años del gobierno de Salvador Allende fue decisiva e intensa. Intensidad que resignificó al arte y a la cultura generando diálogos que transitaron desde un arte comprometido con un discurso revolucionario marxista, que entendía su práctica como la expresión complementaria y difusora de una ideología hasta otras expresiones menos convencionales de la izquierda que consideraban al arte y la escritura como articuladoras ellas mismas de una intervención en los modos de ser y conformar el espacio social, capaz ella misma, en su propia especifidad de producir una nueva subjetividad. Las variantes entre un punto y otro fueron diversas y sus estrategias de colaboración no fueron simplemente marginales y esporádicas. Ya lo vimos en los escritores agrupados bajo el sello Cormorán, que tuvieron importantes relaciones participativas con el proceso de socialización. También es posible distinguir esto en el cine, donde hubo un amplio y diverso repertorio de producciones cinematográficas que fueron desde un cine "comprometido" hasta un cine experimental creado bajo el alero de la Universidad de Chile, todos ellos incorporados a una iniciativa estatal llamada 
Chilefilms. Lo mismo en las artes con artistas como José Balmes, Roser Bru, Roberto Matta, Francisco Brugnoli y otros que lograron producir un arte inclasificable, capaz de propiciar un arte creador y al mismo tiempo, comprometido con relegar al arte con la política. No podemos desconocer una infinidad de conflictos que han dado alimento al ímpetu de la culpa y de su expiación por medio del olvido, tanto al legado renovado de muchos de los que formaron parte de este proceso, como de aquellos que responden a la intensidad de una eternización de un presente neoliberal desencantado. Cabe recordar aquí una frase memorable de Bataille, citado por JeanLuc Nancy:

Para un marxista, un valor allende lo útil es concebible, e incluso inevitable, pero eso no es inmanente al hombre. Lo que trasciende al hombre (y al hombre que naturalmente vive aquí-abajo), o asimismo lo que sobrepasa a la humanidad común (la humanidad sin privilegio), es inadmisible sin discusión. El valor soberano es el hombre: la producción no es el único valor, no es sino el medio para responder a las necesidades del hombre, ella lo sirve, y no el hombre a la producción. (40)

En este sentido, la revista Cormorán nos permite identificar algunos de los conflictos y discusiones que, lejos de considerarse como rupturas, atienden a la naturaleza diversa y experimental que tuve este periodo. El compromiso por preservar la diversidad y oponerse a un reduccionismo de una izquierda empecinada a diagramar sus operaciones desde la dicotomía estructural entre burguesía y proletariado. La propuesta cultural de Cormorán se enmarcó en la ampliación y apertura crítica de todas las formas de pensamiento y a preservar una cierta autonomía relativa del arte en de la política, evitando así concebir al arte como medio expresión de una ideología. Consideró determinante reconocer la fundamentalidad del campo de los relatos y propuestas simbólicas, en tanto desde allí se hace posible desbaratar las estructuras subyacentes a una dependencia cultural que ha disuelto la potencia constructora de la cultura y generado una identidad difusa, incapaz de sostener al conjunto de la sociedad. Por el contrario, proponemos la apuesta de Cormorán desde una articulación más grande de una nueva sociedad y un nuevo hombre, nociones transitadas por distintas tradiciones y miradas de su especificidad. Es un tentativo y abierto proponer de relaciones, entre cuerpos, voces y espacios. Contribuye, sin duda, a lo que Eduardo Vassallo plantea como un cambio más profundo, en el sentido de una propuesta epocal que no solo pretendía terminar con las inequidades sociales, sino mas bien "del empeño casi ni declarado por el trabajo cultural que se viene: asentar y dar vida a una Poética como una morada plenamente solidaria y humana para Chile"(17).

Esta poética se manifiesta como un imaginario colectivo y plural en el que el arte y la cultura son capaces de alterar lo que Rancière denomina el reparto de lo sensible, donde los actos estéticos sirven "[...] como configuraciones de la experiencia, que dan cabida a modos nuevos del sentir e inducen formas nuevas de las subjetividad política" (5) y al mismo tiempo producir una comunidad entendida en palabras de Jean-Luc Nancy como división de tareas que no reconstruye una unidad previa, sino mas bien "como un reparto, y no como una fusión; como una exposición, y no como una inmanencia” (Nancy 128). En su proyecto editorial se manifiesta una continua tensión entre la posibilidad de instrumentalizar al arte desde la política, y se apuesta por hacer de ambos diferentes dimensiones capaces de transformar y provocar una nueva mirada de lo real. Una poética que incorpore un nuevo sentido que surja de una pulsión comunitaria, y no de una pulsión totalitaria. Hay aquí una comprensión del lenguaje y el arte como manifestación de 
una subjetividad, como categoría de una sospecha ante las estructuras conceptuales y epistemológicas. Es un poner en cuestión el presupuesto del lenguaje y la imagen como efectos sólidos, mediadores y, por tanto neutral, capaz de ser usado tanto por una oficialidad momificada o por una vanguardia revolucionaria. Hay un poner en duda, descomponer certezas, para expandir la expresión creativa de un sujeto histórico, enraizado en un presente.

\section{BIBLIOGRAFIA}

Albornóz, César. "La cultura en la Unidad Popular: porque esta vez no se trata de cambiar un presidente." Cuando hicimos historia. La experiencia de la Unidad Popular. Ed. Pinto Vallejos, Julio. Santiago: LOM Ediciones, 2005. 147-75. Print.

Beigel, Fernanda. "Las revistas culturales como documentos de la historia latinoamericana." Utopía y Praxis Latinoamericana. Revista Internacional de Filosofía Iberoamericana y Teoría Social 8.20 (2003): 105-15. Print.

Bowen Silva, Martín. "El proyecto sociocultural de la izquierda chilena durante la Unidad Popular. Crítica, verdad e inmunología política." Nuevo Mundo Mundos Nuevos (2008). Web. 20 de abril de 2012.

Canto Novoa, Nadinne. "El lugar de la cultura en la vía chilena al socialismo. Notas sobre el proyecto estético de la Unidad Popular." Revista Pléyade.9 (Enero-Junio 2012): 153-78. Print.

Cleaver, Eldridge. "Unidad junto a la bandera." Cormorán.4 (1970): 6-7. Print.

Corvalán, Luis, et al. Programa básico de gobierno de la Unidad Popular. Candidatura Presidencial de salvador Allende. Santiago1969. Print.

Diputados, Cámara de. "Encuentro Latinoamericano de escritores." Santiago: Instituto Geográfico Militar, 1969. Print.

Fossey, Jean Michel. "Boquitas pintadas o los años 40: conversación con Manuel Puig." Cormorán.8 (1970): 11. Print.

---. "Con Margarite Duras." Cormorán.7 (1970): 7. Print.

---. "Embajador y escritor." Cormorán.5 (1970): 11. Print.

---. "Entrevista Jean Genet." Cormorán.7 (1970): 3. Print.

---. "Severo Sarduy, par lui même." Cormorán.6 (1970): 4-5. Print.

Gilman, Claudia. Entre la pluma y el fusil. Debates y dilemas del escritor revolucionario en América Latina. Buenos Aires: Siglo veintiuno editores Argentina, 2003. Print.

Huneeus, Cristián. "Las parábolas de William Golding." Cormorán.4 (1970): 11/13. Print.

Lihn, Enrique. "Política y cultura en una etapa de transición al Socialismo." La cultura en la vía chilena al socialismo. Eds. Lihn, Enrique, et al. Imagen de Chile. Santiago: Editorial Universitaria, 1971. 1372. Print.

---. "Un taller de poesía en 1972: Notas y reflexiones de una experiencia de trabajo." El circo en llamas. Ed. Marín, Germán. Santiago: LOM Edicones, 1973. 120-31. Print.

Lihn, Enrique, and Germán Marin. "Festival de cine Latinoamericano." Cormorán.4 (1969): 8-10. Print. Littín, Miguel. "Festival de Cine Latinoamericano (entrevista)." Cormorán.4 (Diciembre 1969): 8-9. Print. Maldonado, Carlos, and Lucho Abarca. "¿Dónde está la política cultural? Teoría ...y práctica." La Quinta Rueda.1 (1972): 12-15. Print.

Marín, Germán. "Líhneas para un prólogo." El circo en Llamas. Ed. Marín, Germán. Santiago: LOM Ediciones, 1996. 7-15. Print.

Marín, Germán, and Enrique Lihn. "Entrevista a Mario Benedetti." Cormorán.5 (1970): 8-10. Print.

Mattelart, Armand, Mabel Piccini, and Michélle Mattelart. Los medios de comunicación de masas. La ideología de la prensa liberal en Chile. Santiago: Cuadernos de la Realidad Nacional, 1970. Print. 
Mouesca, Jacqueline. Plano secuencia de la memoria de Chile: veinticinco años de cine chileno (19601985). Ediciones del litoral. Print.

Nancy, Jean-Luc. La Comunidad inoperante. Trans. Garrido, Juan Manuel. Santiago: LOM Ediciones, 2000. Print.

Onetti, Juan Carlos, and Carlos Martínez Moreno. "De cómo Juan Carlos Onetti y Carlos Martínez Moreno se entrevistaron mutuamente en el nido de Cormorán." Cormorán.7 (1970): 8-11. Print.

Popular, Taller de escritores de la Unidad. "Por la creación de una cultura nacional y popular." Cormorán. 8 (1970): 7-8. Print.

Rama, Ángel. "¿Para qué sirven las revistas?" Marcha.1161 (1963): 30-31. Print.

Rancière, Jacques. El reparto de lo sensible. Santiago: LOM Ediciones, 2009. Print.

s/a. "Editorial." Cormorán.2 (1969): 1-2. Print.

---. "Editorial." Nueva Atenea.423 (1970): 1. Print.

---. "Editorial. Nuevos días, nuevas metas." Cormorán.8 (1970): 2. Print.

Salazar, Gabriel. Labradores, peones y proletarios. Santiago: Ediciones Sur, 1985. Print.

Vassallo, Eduardo. "Notas para un prólogo a la cultura en la Unidad Popular." La cultura con Allende. Tomo I / 1970-71. Eds. Vassallo, Eduardo and Gonzalo Contreras. Vol. I. Santiago: Ediciones Alterables, 2014. 17-32. Print.

Wilson, Edmund. " Scott Fitzgerald en Zig Zag." Cormorán.3 (1969): 4. Print. 